\title{
A new pathway of glucocorticoid action for asthma treatment through the regulation of PTEN expression
}

\author{
ZhenHua Ni ${ }^{\dagger}$, JiHong Tang ${ }^{\dagger}$, ZhuYing Cai, Wei Yang, Lei Zhang, Qingge Chen, Long Zhang and XiongBiao Wang ${ }^{*}$
}

\begin{abstract}
Background: "Phosphatase and tensin homolog deleted on chromosome 10" (PTEN) is mostly considered to be a cancer-related gene, and has been suggested to be a new pathway of pathogenesis of asthma. The purpose of this study was to investigate the effects of the glucocorticoid, dexamethasone, on PTEN regulation.

Methods: OVA-challenged mice were used as an asthma model to investigate the effect of dexamethasone on PTEN regulation. Immunohistochemistry was used to detect expression levels of PTEN protein in lung tissues. The human A549 cell line was used to explore the possible mechanism of action of dexamethasone on human PTEN regulation in vitro. A luciferase reporter construct under the control of PTEN promoter was used to confirm transcriptional regulation in response to dexamethasone.

Results: PTEN protein was found to be expressed at low levels in lung tissues in asthmatic mice; but the expression was restored after treatment with dexamethasone. In A549 cells, human PTEN was up-regulated by dexamethasone treatment. The promoter-reporter construct confirmed that dexamethasone could regulate human PTEN transcription. Treatment with the histone deacetylase inhibitor, TSA, could increase PTEN expression in A549 cells, while inhibition of histone acetylase (HAT) by anacardic acid attenuated dexamethasone-induced PTEN expression.
\end{abstract}

Conclusions: Based on the data a new mechanism is proposed where glucocorticoids treat asthma partly through up-regulation of PTEN expression. The in vitro studies also suggest that the PTEN pathway may be involved in human asthma.

\section{Background}

Bronchial asthma is a chronic inflammatory disorder of the airways, with episodic occurrences of airflow obstruction, and hypersensitivity and hyperresponsiveness to various stimuli. Asthma is one of the most common diseases, occurring in approximately 300 million people of all ages and ethnic backgrounds worldwide $[1,2]$. Many attempts have been made over decades to discover the etiology of the disease, and thousands of papers have been published. Although the mechanism is still not well understood, inflammation has been identified as the main reason that could explain most of the symptoms of asthma $[3,4]$.

\footnotetext{
* Correspondence: xiongbiao6@yahoo.com

† Contributed equally

Department of Respiratory Medicine, Putuo Hospital, Shanghai University of Traditional Chinese Medicine, Shanghai, 200062, PR China
}

Because the dominant pathological feature is airway inflammation, one of the main achievements of the last decade has been the understanding of the inflammation nature of the disease $[4,5]$. In view of the unclear etiology of asthma, the purpose of asthma treatment is to achieve and maintain clinical control. Although the guidelines for asthma management by the Global Initiative for Asthma (GINA) have gone through many revisions since 1989 [6], the status of corticosteroids in this management has been stable because of their most effective anti-inflammatory function. Inhaled glucocorticoids are the most effective control currently available. Systemic administration of glucocorticoids are commonly used in the treatment of severe acute exacerbations because they prevent the progression of asthma exacerbation, reduce the need for referral to emergency departments and hospitalization, prevent early relapse 
after emergency treatment, and reduce the morbidity of the illness. The mechanism of glucocorticoids in asthma therapy has been explored for decades. Genomic and non-genomic mechanisms have been reviewed recently by Alangari [7], and more efforts are still being made to further our understanding of the mechanisms to help with application to therapeutics.

The PTEN (Phosphatase and tensin homolog deleted on chromosome 10) gene has been identified as one of the most commonly lost or mutated tumor suppressor genes in humans. It functions as a plasma-membrane lipid phosphatase that antagonizes the PI3K (phosphoinositide 3 kinase)-AKT pathway. PTEN exerts a wide range of effects on cell growth, migration, death, and differentiation[8]. The gene has drawn interest concerning its potential role in asthma in recent years. It has been confirmed that PTEN expression is down-regulated in an asthma model, and that exogenous PTEN can effectively relieve asthma in these mice [9-11], and reduce chronic airway inflammation and airway remodeling through regulation of IL-17 expression [12]. Administration of peroxisome proliferator-activated receptor gamma (PPARgamma) agonists or AdPPARgamma reduced bronchial inflammation and airway hyperresponsiveness by up-regulating PTEN expression in allergen-induced asthmatic lungs [13]. It has been found recently that PTEN can inhibit human airway smooth muscle cell migration [14] as well as endothelial nitric oxide synthase [15], which, in turn, inhibit airway inflammation. Because of these facts, PTEN has been proposed as a therapeutic target for asthma [16]. PTEN acts as the catalytic antagonist of PI3K by dephosphorylating PIP3 to PIP2. PI3Kbeta, delta and gamma isoform-specific PI3K inhibitors (TGX-221, IC87114 and AS-605240) have been developed for asthma treatment [17].

The evidence for the involvement of PTEN in asthma in humans, however, is rare. Moreover, there are no available data on the effects of glucocorticoids on PTEN expression. In this study, we discovered that dexamethasone could upregulate PTEN expression in mice and in a human lung epithelial cell line. We also describe a new signaling pathway for steroids in asthma.

\section{Methods}

\section{OVA-induced mouse model of asthma}

All experimental procedures conformed to international standards of animal welfare, and were approved by the Institute Animal Care and Use Committee of Shanghai University of Traditional Chinese Medicine. Female BALB/c mice were purchased from Shanghai SLAC Laboratory Animal Co. Ltd. All mice were kept in wellcontrolled animal housing facilities, and had free access to tap water and food pellets throughout the experimental period. Female, 6-8-week-old BALB/c mice $(n=30)$ were divided into three groups: OVA-treated group (OVA-challenged mice treated with saline), OVA+dexamethasone-treated group (OVA-challenged mice treated with dexamethasone) and a saline-group (saline-challenged mice treated with saline). Mice were challenged with Ovalbumin (OVA) (Grade V; Sigma Aldrich, Shanghai, China) by intraperitoneal and intranasal routes. OVA treated $(n=10)$ and dexamethasone treated $(\mathrm{OVA} / \mathrm{DM})(n=10)$ groups were immunized by intraperitoneal (i.p.) injections of $100 \mu \mathrm{g}$ of OVA mixed with potassium aluminum sulfate on days 0 and 14 [18]. Mice received an intranasal dose of $500 \mu \mathrm{g}$ OVA on days $14,25,26,27$. The control group $(n=10)$ received normal saline with alum i.p. on days 0 and 14 and normal saline without alum intranasally on days $14,25,26$, 27 [19]. The group of dexamethasone-treated mice was administered with dexamethasone intraperitoneally (1.7 $\mathrm{mg} / \mathrm{kg}$, once a day) beginning on day 28 of the protocol and continuing until day 41. Animals were sacrificed by i.p. injection of pentobarbital at day 42, and the lungs and extrahilar tracheobronchial airways were rapidly dissected out.

\section{Tissue processing and immunohistochemistry analysis}

Immunohistochemistry detection of PTEN was done as described elsewhere [9]. Tissue sections from the right lungs were first treated with PTEN antibody (R\&D Systems, Minneapolis, MN, USA). After incubation at $4{ }^{\circ} \mathrm{C}$ overnight, tissue sections were washed with PBS, and treated with ligation enhancing buffer (Maixin Bio, FuZhou, China)) for $30 \mathrm{~min}$ at room temperature. Tissue sections were then washed with PBS, and treated for $30 \mathrm{~min}$ with horseradish peroxidase (HRP)-anti-rabbit IgG (Maixin Bio). The color was developed using diaminobenzidine (DAB). The intensity of PTEN protein staining was determined as an average optical density by IPP software (Image-Pro Plus 6.0, Media, Cybernetics). A nonstained region was selected and set as the background.

\section{Cell culture}

The lung epithelial cell line, A549, was purchased from the Institute of Cell Biology (Shanghai, China), and cultured in RMPI1640 medium (Gibco, Shanghai, China) supplemented with $10 \%$ fetal bovine serum, penicillin and streptomycin. A549 cells were treated with the indicated concentrations of dexamethasone for $24 \mathrm{~h}$. Otherwise, the cells were treated with $1 \times 10^{-5} \mathrm{M}$ dexamethasone. The cells were harvested at 24 h, 48 h, 72 h, and 96 h.

\section{PTEN expression analysis by real-time quantitative PCR}

Total RNA from A549 cells were extracted by Trizol (Invitrogen Life Technologics, Carlsbad, CA, USA). The RNA $(0.5 \mu \mathrm{g})$ was reverse transcribed to cDNA, using a RevertAid First Strand cDNA Synthesis Kit (Fermentas, 
ShenZhen, China). Quantitative real-time PCR was performed by Universal Master Mixer (Roche Applied Science, Shanghai, China) on a 7300 Real-time PCR System (Applied Biosystems, Foster City, CA, USA). The primers and probes used are listed in Table 1. Each assay was performed in triplicate. The PCR conditions used in all reactions were: $10 \mathrm{~min}$ at $95^{\circ} \mathrm{C}$, followed by 40 two-step cycles $\left(95^{\circ} \mathrm{C}\right.$ for $15 \mathrm{~s}$ and $60^{\circ} \mathrm{C}$ for $45 \mathrm{~s}$ ). The relative expression levels of the PTEN gene were normalized against GAPDH and analyzed by the $2^{-\Delta \Delta C t}$ method $\left[\Delta \Delta \mathrm{Ct}=\left(\mathrm{Ct}_{\text {PTEN }}-\mathrm{Ct} \mathrm{GAPDH}_{\text {sample }}-\left(\mathrm{Ct}_{\text {PTEN }}\right.\right.\right.$ - $\mathrm{Ct}$ GAPDH $)_{\text {control] }}$.

\section{Reporter construct, transient transfections and luciferase assays}

The PTEN promoter sequence was amplified from human blood cells. Primers were designed according to human genomic PTEN (GenBank accession no. AF067844, Table 1). To construct pGL3-PTEN, amplified DNA fragments were digested with Kpn I and Bgl II, and subcloned into the pGL3-basic vector (Promega, Madison, WI, USA). Before transfection, A549 cells were plated in 24-well plates at a density of 50,000 cells/ well and grown overnight. Cells were co-transfected with $0.8 \mu \mathrm{g} /$ well of the pGL3-PTEN construct and 0.5 ng/well Renilla luciferase control plasmid (PRL-SV40) by Lipofectmine 2000 (Invitrogen, Shanghai, China). After $24 \mathrm{~h}$, cells were treated with dexamethasone for another $24 \mathrm{~h}$. Luciferase activity was assayed by using a dual-luciferase reporter assay system (Promega) on a luminometer (GloMax 20/20, Promega).

\section{Trichostatin A (TSA) and anacardic acid treatment}

To analyze the relationship among dexamethasone, histone acetylation and PTEN expression, the A549 cell line was allowed to grow overnight to $70 \%$ confluency in 6 well plates. The next day, TSA (Sigma, Shanghai,

Table 1 Sequences of primers and probes

\begin{tabular}{|c|c|}
\hline Primers or Probes & Sequence \\
\hline $\begin{array}{l}\text { Forward Primer } \\
\text { (PTEN) }\end{array}$ & 5'-GGGACGAACTGGTGTAATGATATG-3' \\
\hline $\begin{array}{l}\text { Reverse Primer } \\
\text { (PTEN) }\end{array}$ & 5'-ATAGCGCCTCTGACTGGGAATAG-3' \\
\hline $\begin{array}{l}\text { TaqMan Probe } \\
\text { (PTEN) }\end{array}$ & $\begin{array}{c}\text { 5'-fam- CCCTIITTGTCTCTGGTCCTTACTTCCCC } \\
\text {-tamra-3' }\end{array}$ \\
\hline $\begin{array}{l}\text { Forward Primer } \\
\text { (GADPH) }\end{array}$ & 5'-CCACTCCTCCACCTITGAC-3' \\
\hline $\begin{array}{l}\text { Reverse Primer } \\
\text { (GADPH) }\end{array}$ & 5'-ACCCTGTTGCTGTAGCCA-3' \\
\hline $\begin{array}{l}\text { TaqMan Probe } \\
\text { (GADPH) }\end{array}$ & 5'-fam- TTGCCCTCAACGACCACTTGTC -tamra-3' \\
\hline PTEN promoter-F & 5'-GGGGTACCGTGTATCCTTCCACCTCC-3' \\
\hline PTEN promoter-R & 5'-GAAGATCTGGCCTCGCCTCACAGCGGCTCAACTC-3 \\
\hline
\end{tabular}

China) were added directly to the cells to a final concentration of $1 \mu \mathrm{mol} / \mathrm{L}$. An equivalent volume of vehicle (DMSO) was added to the control. After a $24 \mathrm{~h}$ incubation, cells were harvested and total RNA was prepared as described for RT-PCR analysis. In anacardic acid (Sigma) experiments, cells were treated with dexamethasone $\left(10^{-5} \mathrm{M}\right)$ alone or dexamethasone $\left(10^{-5} \mathrm{M}\right)$ plus anacardic acid $(20 \mu \mathrm{mol} / \mathrm{L})$ for $24 \mathrm{~h}$.

\section{Statistical analysis}

Results were expressed as the mean \pm SD. Variance analysis was used for statistical comparisons between groups by Student's t-test. Statistical significance was set at $\mathrm{p}<0.05$.

\section{Results}

Restoration of PTEN expression in OVA-treated mice with dexamethasone

The lung tissues in the dexamethasone treated groups had a marked inhibition of OVA-induced inflammation including lower infiltration of eosinophils and lymphocyte, decreased of airway smooth muscle thickening and collagen deposition (Figure 1A-C), which are consistent with published data [20,21]. Immunohistochemistry was used to detect the PTEN protein expression level in lung tissue. PTEN was expressed mainly in epithelial

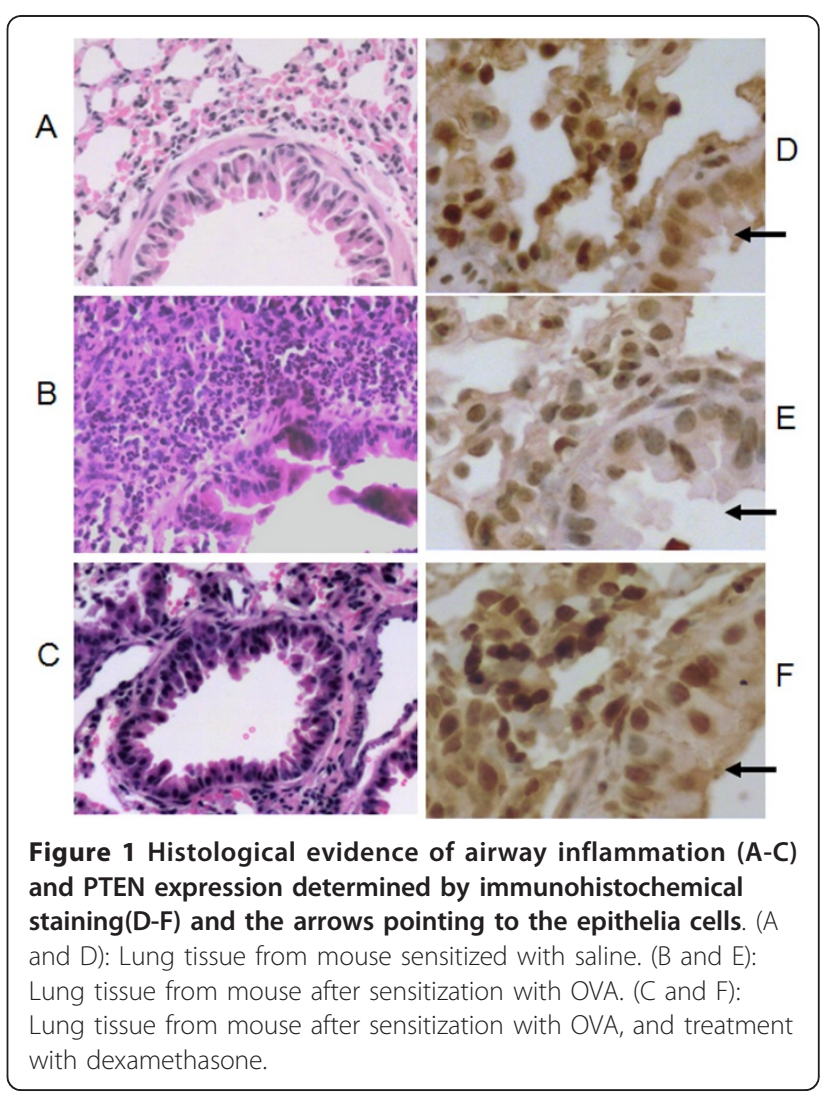


layers around the bronchioles (Figure 1D). This immunoreactive PTEN protein was under-expressed in the OVA-treated group compared with the saline control groups (Figure 1E). However, when mice in the OVAtreated group were treated with dexamethasone, the PTEN expression in lung tissues was restored (Figure 1F). The average optical density was measured also (Figure 2). The OVA-treated group showed a significantly lower density compared with the saline group $(p=0.007)$ and OVA plus dexamethasone $(p=0.008)$.

\section{Dexamethasone promotes the expression of PTEN by stimulating PTEN transcription}

To further confirm the role of dexamethasone in PTEN expression, human A549 lung epithelial cells were treated with dexamethasone at the concentration $10^{-5} \mathrm{M}-10^{-}$ ${ }^{8} \mathrm{M}$ for $24 \mathrm{~h}$, or at the concentration $10^{-5} \mathrm{M}$ and harvested at 24, 48, 72, $96 \mathrm{~h}$. The expression of PTEN mRNA was analyzed by real-time PCR. As shown in Figure $3 \mathrm{~A}$ and $3 \mathrm{~B}$, dexamethasone treatment increased PTEN mRNA expression in a dose- and time-dependent manner, indicating that the effects of dexamethasone on PTEN expression might have occurred at the transcriptional level. To confirm this hypothesis, the PTEN promoter was cloned and constructed into the pGL3 luciferase plasmid, as described in the Methods section. We found that dexamethasone $\left(10^{-5} \mathrm{M}\right)$ treatment significantly increased the PTEN promoter activity (Figure $3 \mathrm{C}$ ), indicating that dexamethasone promoted the expression of PTEN by stimulating PTEN transcription.

\section{The effect of acetylation of histone on the regulation of PTEN expression}

As histone acetylation is one of the important mechanisms for the effect of glucocorticoids [22], we hypothesized that

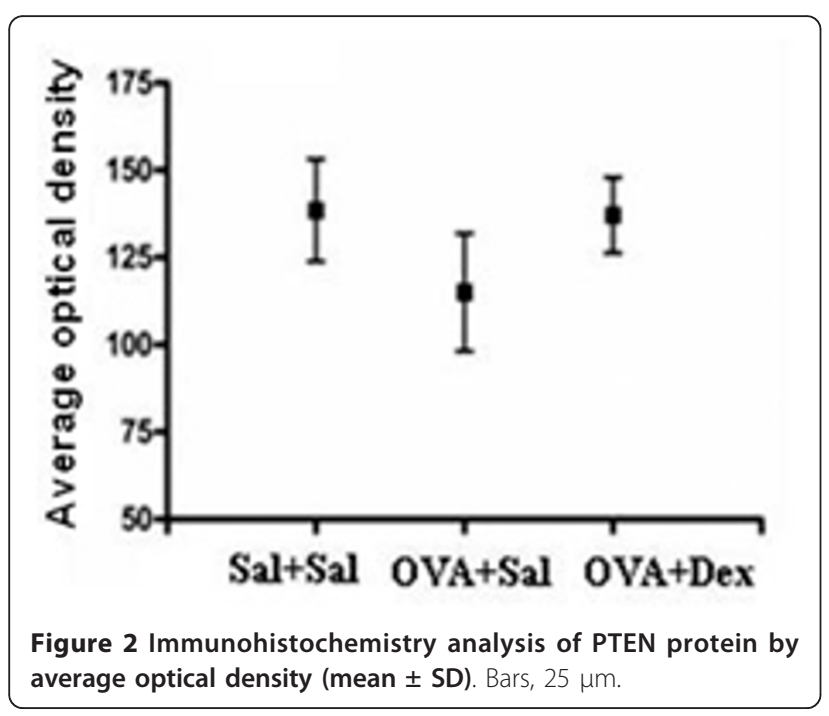

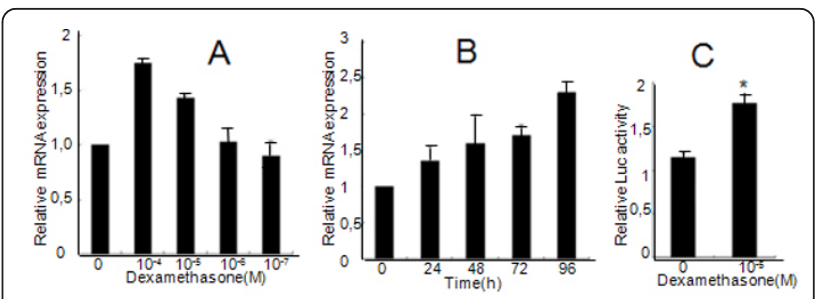

Figure 3 Effect of dexamethasone on PTEN regulation in A549 cells. A representative of three independent experiments is shown. (A): A549 cells were treated with dexamethasone at the indicated concentrations for $24 \mathrm{~h}$. (B): A549 cells were treated with dexamethasone $\left(10^{-5} \mathrm{M}\right)$ for $24 \mathrm{~h}, 48 \mathrm{~h}, 72 \mathrm{~h}$ and $96 \mathrm{~h}$. The PTEN mRNA level was measured by quantitative real-time PCR. (C): A549 cells were transfected with the PTEN promoter luciferase plasmid for $24 \mathrm{~h}$ and treated with $10^{-5} \mathrm{M}$ dexamethasone for another $24 \mathrm{~h}$. The luciferase levels were obtained from three experiments performed in duplicate. ${ }^{*} p<0.05$ vs control group $(p=0.0003)$.

the regulation of PTEN expression by dexamethasone might involve histone acetylation. We treated A549 cells first with TSA, and confirmed that histone deacetylase inhibition was associated with the up-regulation of PTEN transcription $(p=0.006)$ (Figure 4$)$, an observation that was consistent with a previous report [23]. We then treated A549 cells with dexamethasone $\left(10^{-5} \mathrm{M}\right)$ plus the histone acetylase inhibitor anacardic acid $(20 \mu \mathrm{mol} / \mathrm{L})$ for 24 $\mathrm{h}$. We extracted the total RNA and analyzed it by realtime PCR. We found that dexamethasone $\left(10^{-5} \mathrm{M}\right)$ alone increased PTEN mRNA expression, whereas treatment

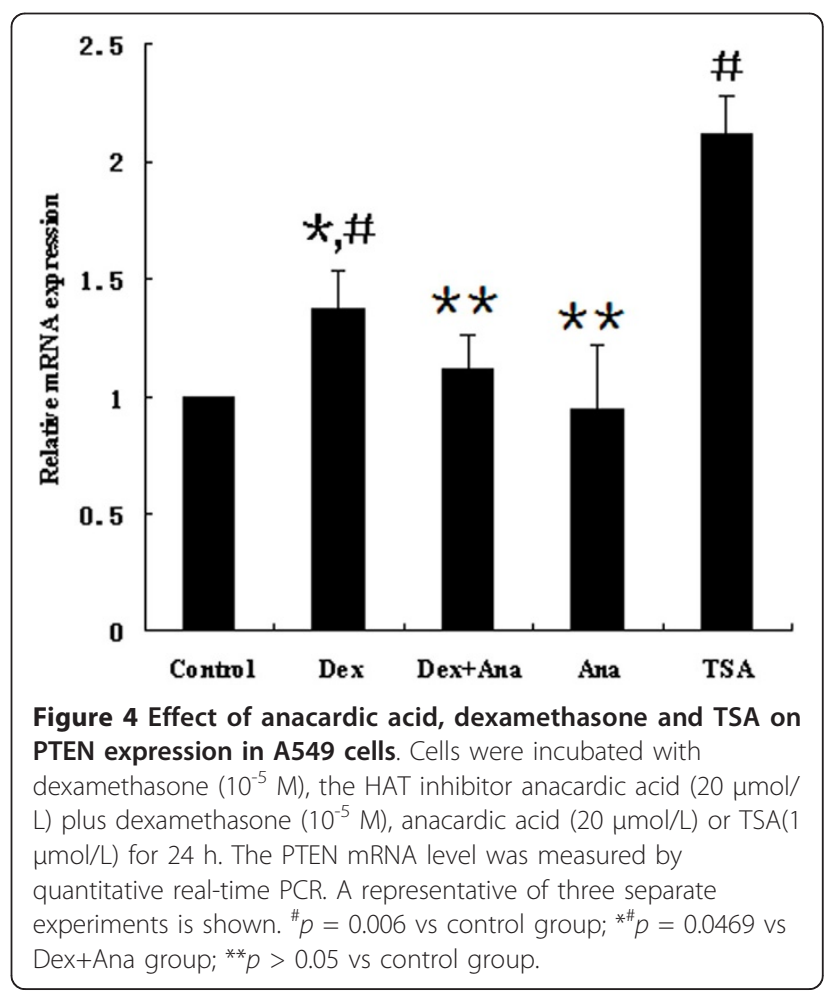


with anacardic acid attenuated the dexamethasoneinduced up-regulation of PTEN mRNA (Figure 4), indicating that histone acetylation inhibition is involved in the dexamethasone-induced PTEN expression.

\section{Discussion}

OVA-induced asthma mice model is widely used for study of human asthma because of resemblance pathology and pathophysiology. Based on this model, we confirmed that PTEN proteins were under-expressed in mice with OVAinduced asthma. We also found that treatment of these mice with dexamethasone resulted in the restoration of PTEN expression. In vitro studies using human lung epithelial cell A549 revealed that dexamethasone was able to increase both PTEN promoter activity and gene expression. Data from all these assays together suggest that the effect of glucocorticoids on asthma may partly pass through the PTEN signaling pathway, and that PTEN is a new target gene involved in the response to dexamethasone. Although PTEN is a highly conserved gene with more than $80 \%$ identity in the promoter region between Homo sapiens and Mus musculus, more valuable data may be derived from humans. Thus, further studies in asthma patients is necessary.

The mechanisms of glucocorticoids in anti-inflammatory treatment for asthma have been investigated extensively. These studies were focused on different targets of airway or different gene expression, and had provided some answers regarding the mechanisms. The target cells studied for glucocorticoid action were mainly airway epithelial cells [24], airway smooth muscle cells [25-29], and inflammatory cells, such as mast cells [30] and monocytes [31,32]. All these effects could also be divided into genomic and non-genomic mechanisms depending on gene expression [7]. More studies will continue to draw a full picture of the mechanisms of glucocorticoids in asthma therapy. Here a new mechanism is proposed: glucocorticoids up-regulate PTEN transcription, and PTEN, in turn, inhibits inflammation.

As described above, PTEN maybe a target for asthma treatment. Regulation of PTEN expression is a key for this therapy. PTEN regulation has been the subject of many studies [33-35]. Recent studies revealed that simvastatin, pravastatin, fluvastatin, dietary exposure to the soy isoflavone genistein (GEN) and phytoestrogens induce PTEN expression in mammary epithelial cells in vivo and in vitro [36,37]. Trichostatin A (TSA) could up-regulate PTEN transcription [23]. The venom of the scorpion Buthus martensii Karsch upregulates the expression of PTEN, accompanied by decreased levels of Akt and Bad phosphorylation [38]. However, TGF- $\beta 1$, estrogen, and PRL-3 could down-regulate PTEN expression $[39,40]$. There are few reagents that can specifically regulate PTEN expression in the airways. We believe more efforts should be made in this area.
With respect to the regulation inflammatory genes, glucocorticoids increase gene expression through alterations in chromatin structure by histone acetylation and recruitment of RNA polymerase II to the promoter site. This, in turn, results in the activation of gene transcription [41]. We have tested whether histone acetylation participates in the regulation of dexamethasone-induced PTEN transcription. As shown in Figure 3, the histone acetylase inhibitor anacardic acid inhibited dexamethasone-induced PTEN up-regulation in mRNA levels, indicating that histone acetylase inhibition is associated with transcriptional stimulation of the PTEN gene by dexamethasone. Our results are supported by the findings of Ito et al. [42] that high concentrations dexamethasone $\left(>10^{-8} \mathrm{M}\right)$ produce a time- and concentration-dependent increase in histone acetylation in A549 cells, resulting in the recruitment of the activated transcription complex, and the subsequent increase in the expression of several genes.

The direct effect of glucocorticoids on transcript activation occurs through binding and activation glucocorticoid receptors (GR), which results in the translocation of glucocorticoid-receptor complexes to the nucleus and binding to glucocorticoid response elements (GREs) in the promoter region of target genes [43]. GREs are short sequences of DNA within the promoter that are able to bind glucocorticoid-receptor complexes and therefore regulate gene transcription. The typical DNA sequence of the GRE is 5'-GGTACAnnnTGTTCT-3' [44]. However, this typical response element could not be found in the 5'-upstream region of the PTEN gene. Several studies have reported several alternative GREs, in addition to the typical GRE [45-47]. These GREs have some variability at several nucleotide positions. Among them, the sequence 5'-TGTNC-3' was reported to be a pentamer GRE core sequence [47]. We screened the promoter region of PTEN (from -778 to -2141) for homology to this sequence. Two regions with the highest homology are at positions -1360 to -1364 , and -1604 to -1608 , both with the sequence 5'-TGTGC-3'. Further investigations are necessary to answer whether glucocorticoids increase PTEN expression by direct binding to these two putative GREs in the PTEN promoter region, or by interfering with the binding of other transcription factors.

In fact, the number of genes directly regulated by glucocorticoids was limited, whereas many genes were indirectly regulated through an interaction with other transcription factors and coactivators. Pan et al. reported that p300 could promote PTEN expression [23]. Wang et al. reported that dexamethasone treatment increased SRC-1, CBP and p300 recruited to the PEPCK gene promoter [48]. Recruitment of these transcription factors promotesd large protein complexes such as RNApolymerase II binding to the promoter region. Therefore it 
was very likely that these transcription factors participated in dexamethasone-induced PTEN regulation.

Here we propose a new signaling pathway of antiinflammatory responses. Glucocorticoid up-regulates PTEN expression, which dephosphorylates the signal lipid PIP3 and down-regulates PIP3/AKT actions in turn. As main inflammatory mediators, the downstream targets are inhibited, thus, asthma could be controlled.

\section{Conclusion}

Our study indicates that dexamethasone increases the expression of PTEN in asthmatic mice and human A549 cells. This induction results from the stimulation of PTEN transcription, and may involve the increased histone acetylation at the PTEN promoter. A new mechanism of action is proposed for the anti-inflammatory effect of glucocorticoids in asthma treatment. Specific regulation of PTEN expression in human airways may be useful for the treatment of asthma.

\section{Declaration of interests}

The authors declare that they have no competing interests. The authors alone are responsible for the content and writing of the paper.

\section{List of abbreviations}

GR: glucocorticoid receptors; GREs: glucocorticoid response elements; HAT: histone acetylase; OVA: ovalbumin; PI3K: phosphoinositide 3 kinase; PPARgamma: peroxisome proliferator-activated receptor gamma; PTEN: Phosphatase and tensin homolog deleted on chromosome 10; TSA: trichostatin A

\section{Acknowledgements}

This work was supported by the Shanghai Science and Technology Committee (No.09JC1412900, No.10411969100), the Shanghai educational Committee(No.10YZ54).

\section{Authors' contributions}

ZHN carried out the molecular studies and drafted the manuscript. JHT participated in the design of the study and carried out cell culture. ZYC carried out the assays of reporter construct. WY performed the statistical analysis. LZ carried out immunohistochemistry. QGC and LZ carried out animal studies. XBW conceived the study, and participated in its design and coordination and helped to draft the manuscript. All authors read and approved the final manuscript.

\section{Authors' information}

Wang XB, Ph.D., M.D., Director of the Department of Respiratory Medicine, Putuo hospital, Shanghai university of Chinese Medicine, The Ph.D. was conferred by Karolinska Institute, Sweden in 2003. The research area is mainly focused on immunol regulation and 17 articles have been published in peer-reviewed journals.

Received: 25 December 2010 Accepted: 14 April 2011 Published: 14 April 2011

\section{References}

1. Bateman ED, Hurd SS, Barnes PJ, Bousquet J, Drazen JM, FitzGerald M, Gibson P, Ohta K, O'Byrne P, Pedersen SE, et al: Global strategy for asthma management and prevention: GINA executive summary. Eur Respir J 2008, 31(1):143-178.
2. Subbarao P, Mandhane PJ, Sears MR: Asthma: epidemiology, etiology and risk factors. CMAJ 2009, 181(9):E181-190.

3. Szekely Jl, Pataki A: Recent findings on the pathogenesis of bronchial asthma. Acta Physiol Hung 2009, 96(4):385-405.

4. Murphy DM, O'Byrne PM: Recent advances in the pathophysiology of asthma. Chest 2010, 137(6):1417-1426.

5. Partridge MR: Asthma: 1987-2007. What have we achieved and what are the persisting challenges? Prim Care Respir J 2007, 16(3):145-148.

6. Kroegel C: Global Initiative for Asthma (GINA) guidelines: 15 years of application. Expert Rev Clin Immunol 2009, 5(3):239-249.

7. Alangari AA: Genomic and non-genomic actions of glucocorticoids in asthma. Ann Thorac Med 2010, 5(3):133-139.

8. Hill R, Wu H: PTEN, stem cells, and cancer stem cells. J Biol Chem 2009, 284(18):11755-11759.

9. Kwak YG, Song CH, Yi HK, Hwang PH, Kim JS, Lee KS, Lee YC: Involvement of PTEN in airway hyperresponsiveness and inflammation in bronchial asthma. J Clin Invest 2003, 111(7):1083-1092.

10. Lee YC: The role of PTEN in allergic inflammation. Arch Immunol Ther Exp (Warsz) 2004, 52(4):250-254.

11. Lee KS, Kim SR, Park SJ, Lee HK, Park HS, Min KH, Jin SM, Lee YC: Phosphatase and tensin homolog deleted on chromosome 10 (PTEN) reduces vascular endothelial growth factor expression in allergeninduced airway inflammation. Mol Pharmacol 2006, 69(6):1829-1839.

12. Kim SR, Lee KS, Park SJ, Min KH, Lee KY, Choe YH, Lee YR, Kim JS, Hong SJ, Lee YC: PTEN down-regulates IL-17 expression in a murine model of toluene diisocyanate-induced airway disease. J Immunol 2007. 179(10):6820-6829

13. Lee KS, Park SJ, Hwang PH, Yi HK, Song CH, Chai OH, Kim JS, Lee MK, Lee YC: PPAR-gamma modulates allergic inflammation through upregulation of PTEN. FASEB J 2005, 19(8):1033-1035.

14. Lan H, Zhong H, Gao Y, Ren D, Chen L, Zhang D, Lai W, Xu J, Luo Y: The PTEN tumor suppressor inhibits human airway smooth muscle cell migration. Int J Mol Med 2010, 26(6):893-899.

15. Church JE, Qian J, Kumar S, Black SM, Venema RC, Papapetropoulos A Fulton DJ: Inhibition of endothelial nitric oxide synthase by the lipid phosphatase PTEN. Vascul Pharmacol 2010, 52(5-6):191-198.

16. Kim SR, Lee YC: PTEN as a unique promising therapeutic target for occupational asthma. Immunopharmacol Immunotoxicol 2008, 30(4):793-814

17. Kong D, Yamori T: Advances in development of phosphatidylinositol 3kinase inhibitors. Curr Med Chem 2009, 16(22):2839-2854

18. Lee H, Han AR, Kim Y, Choi SH, Ko E, Lee NY, Jeong JH, Kim SH, Bae H: A new compound, $1 \mathrm{H}, 8 \mathrm{H}$-pyrano[3,4-c]pyran-1,8-dione, suppresses airway epithelial cell inflammatory responses in a murine model of asthma. Int J Immunopathol Pharmacol 2009, 22(3):591-603.

19. Zhang Y, Lamm WJ, Albert RK, Chi EY, Henderson WR Jr, Lewis DB: Influence of the route of allergen administration and genetic background on the murine allergic pulmonary response. Am J Respir Crit Care Med 1997, 155(2):661-669.

20. Chen PF, Luo YL, Wang W, Wang JX, Lai WY, Hu SM, Cheng KF, Al-Abed Y: ISO-1, a macrophage migration inhibitory factor antagonist, inhibits airway remodeling in a murine model of chronic asthma. Mol Med 2010, 16(9-10):400-408.

21. Korideck $H$, Peterson JD: Noninvasive quantitative tomography of the therapeutic response to dexamethasone in ovalbumin-induced murine asthma. J Pharmacol Exp Ther 2009, 329(3):882-889.

22. Adcock IM, Ito K, Barnes PJ: Glucocorticoids: effects on gene transcription. Proc Am Thorac Soc 2004, 1(3):247-254.

23. Pan L, Lu J, Wang X, Han L, Zhang Y, Han S, Huang B: Histone deacetylase inhibitor trichostatin a potentiates doxorubicin-induced apoptosis by up-regulating PTEN expression. Cancer 2007, 109(8):1676-1688.

24. Andersson K, Shebani EB, Makeeva N, Roomans GM, Servetnyk Z: Corticosteroids and montelukast: effects on airway epithelial and human umbilical vein endothelial cells. Lung 2010, 188(3):209-216.

25. Misior AM, Deshpande DA, Loza MJ, Pascual RM, Hipp JD, Penn RB: Glucocorticoid- and protein kinase A-dependent transcriptome regulation in airway smooth muscle. Am J Respir Cell Mol Biol 2009, 41(1):24-39.

26. Lakser OJ, Dowell ML, Hoyte FL, Chen B, Lavoie TL, Ferreira C, Pinto LH, Dulin NO, Kogut P, Churchill J, et al: Steroids augment relengthening of 
contracted airway smooth muscle: potential additional mechanism of benefit in asthma. Eur Respir J 2008, 32(5):1224-1230.

27. Goto K, Chiba Y, Sakai H, Misawa M: Glucocorticoids inhibited airway hyperresponsiveness through downregulation of CPI-17 in bronchial smooth muscle. Eur J Pharmacol 2008, 591(1-3):231-236.

28. Nino G, Hu A, Grunstein JS, Grunstein MM: Mechanism of glucocorticoid protection of airway smooth muscle from proasthmatic effects of longacting beta2-adrenoceptor agonist exposure. J Allergy Clin Immunol 2010, 125(5):1020-1027.

29. Goto K, Chiba Y, Sakai H, Misawa M: Mechanism of inhibitory effect of prednisolone on RhoA upregulation in human bronchial smooth muscle cells. Biol Pharm Bull 2010, 33(4):710-713.

30. Zhou J, Liu DF, Liu C, Kang ZM, Shen XH, Chen YZ, Xu T, Jiang CL: Glucocorticoids inhibit degranulation of mast cells in allergic asthma via nongenomic mechanism. Allergy 2008, 63(9):1177-1185.

31. Khanduja KL, Kaushik G, Khanduja S, Pathak CM, Laldinpuii J, Behera D: Corticosteroids affect nitric oxide generation, total free radicals production, and nitric oxide synthase activity in monocytes of asthmatic patients. Mol Cell Biochem 2011, 346(1-2):31-37.

32. Bhavsar PK, Levy BD, Hew MJ, Pfeffer MA, Kazani S, Israel E, Chung KF: Corticosteroid suppression of lipoxin A4 and leukotriene B4 from alveolar macrophages in severe asthma. Respir Res 2010, 11:71.

33. Tamguney T, Stokoe D: New insights into PTEN. J Cell Sci 2007, 120(Pt 23):4071-4079

34. Gericke A, Munson M, Ross AH: Regulation of the PTEN phosphatase. Gene 2006, 374:1-9.

35. Wang X, Jiang X: Post-translational regulation of PTEN. Oncogene 2008, 27(41):5454-5463.

36. Rahal OM, Simmen RC: PTEN and p53 cross-regulation induced by soy isoflavone genistein promotes mammary epithelial cell cycle arrest and lobuloalveolar differentiation. Carcinogenesis 2010, 31(8):1491-1500.

37. Teresi RE, Planchon SM, Waite KA, Eng C: Regulation of the PTEN promoter by statins and SREBP. Hum Mol Genet 2008, 17(7):919-928.

38. Gao F, Li H, Chen YD, Yu XN, Wang R, Chen XL: Upregulation of PTEN involved in scorpion venom-induced apoptosis in a lymphoma cell line. Leuk Lymphoma 2009, 50(4):633-641.

39. Smith JA, Zhang R, Varma AK, Das A, Ray SK, Banik NL: Estrogen partially down-regulates PTEN to prevent apoptosis in VSC4.1 motoneurons following exposure to IFN-gamma. Brain Res 2009, 1301:163-170.

40. Yang Y, Zhou F, Fang Z, Wang L, Li Z, Sun L, Wang C, Yao W, Cai X, Jin J, et al: Post-transcriptional and post-translational regulation of PTEN by transforming growth factor-beta1. J Cell Biochem 2009, 106(6):1102-1112.

41. Hayashi R, Wada H, Ito K, Adcock IM: Effects of glucocorticoids on gene transcription. Eur J Pharmacol 2004, 500(1-3):51-62.

42. Ito K, Barnes PJ, Adcock IM: Glucocorticoid receptor recruitment of histone deacetylase 2 inhibits interleukin-1 beta-induced histone $\mathrm{H} 4$ acetylation on lysines 8 and 12. Mol Cell Biol 2000, 20(18):6891-6903.

43. Freishtat RJ, Nagaraju K, Jusko W, Hoffman EP: Glucocorticoid efficacy in asthma: is improved tissue remodeling upstream of anti-inflammation. $J$ Investig Med 2010, 58(1):19-22.

44. Schoneveld OJ, Gaemers IC, Lamers WH: Mechanisms of glucocorticoid signalling. Biochim Biophys Acta 2004, 1680(2):114-128.

45. Chen Y, Ferguson SS, Negishi M, Goldstein JA: Identification of constitutive androstane receptor and glucocorticoid receptor binding sites in the CYP2C19 promoter. Mol Pharmacol 2003, 64(2):316-324.

46. Nakabayashi $H$, Koyama Y, Sakai M, Li HM, Wong NC, Nishi S: Glucocorticoid stimulates primate but inhibits rodent alpha-fetoprotein gene promoter. Biochem Biophys Res Commun 2001, 287(1):160-172.

47. Kraus J, Woltje M, Hollt V: Regulation of mouse somatostatin receptor type 2 gene expression by glucocorticoids. FEBS Lett 1999, 459(2):200-204.

48. Wang XL, Herzog B, Waltner-Law M, Hall RK, Shiota M, Granner DK: The synergistic effect of dexamethasone and all-trans-retinoic acid on hepatic phosphoenolpyruvate carboxykinase gene expression involves the coactivator p300. J Biol Chem 2004, 279(33):34191-34200.

doi:10.1186/1465-9921-12-47

Cite this article as: Ni et al:: A new pathway of glucocorticoid action for asthma treatment through the regulation of PTEN expression.

Respiratory Research 2011 12:47.

\section{Submit your next manuscript to BioMed Central and take full advantage of:}

- Convenient online submission

- Thorough peer review

- No space constraints or color figure charges

- Immediate publication on acceptance

- Inclusion in PubMed, CAS, Scopus and Google Scholar

- Research which is freely available for redistribution

Submit your manuscript at www.biomedcentral.com/submit
Biomed Central 